\title{
O enigma da política industrial no Brasil
}

\author{
JOSÉ TAVARES DE ARAUJO JR.*
}

\begin{abstract}
RESUMO: Ao longo dos últimos 10 anos, o governo brasileiro lançou vários planos para promover a inovação da indústria e reforçar sua competitividade a nível nacional. No entanto, os resultados têm se mostrado pobres devido às distorções criadas por alguns instrumentos herdados da época da substituição de importações, tais como altas tarifas sobre bens intermediários e de máquinas, regras de conteúdo local e proteção antidumping. Este artigo destaca o papel desempenhado por esses instrumentos usando dois exemplos: investigações antidumping e uma regra de conteúdo local peculiar que só existe no Brasil, o chamado Processo Produtivo Básico (PPB).
\end{abstract}

PALAVRAS-CHAVE: política industrial; antidumping; regras de conteúdo local.

ABSTRACT: The puzzle of the industrial policy in Brazil. Over the last 10 years, the Brazilian government has launched several industrial plans to promote innovation and strengthen the competitiveness of the domestic industry. However, the results have been poor due to the distortions created by some instruments inherited from the import substitution age, such as high tariffs on intermediate goods and machinery, local content rules and antidumping protection. This paper highlights the role played by those instruments using two examples: antidumping investigations and a peculiar local content rule that exists only in Brazil, the so-called Basic Productive Process (PPB).

KEYWORDS: industrial policy; antidumping; local content rules.

JEL Classification: L52.

\section{INTRODUÇÃO}

Uma das contribuições da literatura recente que restaurou a reputação acadêmica da noção de política industrial foi a de haver substituído as antigas teses de prote-

\footnotetext{
* Diretor do Centro de Estudos de Integração e Desenvolvimento (Cindes) - Brasil. E-mail: jtavares@ cindesbrasil.org. Trabalho preparado para o $11^{\circ}$ Fórum de Economia da Fundação Getulio Vargas. São Paulo, 15 e 16 de setembro de 2014. Este texto foi beneficiado pelas discussões do Grupo de Trabalho de Política Comercial do Cindes, integrado por Edmar Bacha, Eduardo Augusto Guimarães, Lia Valls Pereira, Pedro Cavalcanti Ferreira, Pedro da Motta Veiga, Regis Bonelli e Sandra Polónia Rios (Cindes, 2013). Os argumentos aqui apresentados são, no entanto, da exclusiva responsabilidade do autor. Submetido: 18/agosto/2014; Aprovado: 12/setembro/2014.
} 
ção à indústria nascente e promoção de campeões nacionais por modelos teóricos que procuram esclarecer os vínculos entre inovação, estratégias de competição e incentivos governamentais (Acemoglu et al., 2013; Aghion et al., 2012; Cohen, 2006; Edquist e Chaminade, 2006). Com base nestes modelos, é possível estudar um dos aspectos centrais dos padrões contemporâneos de organização industrial, que tem sido a interação entre o custo crescente da inovação tecnológica e a fragmentação da produção nas indústrias de montagem, advinda do declínio radical nos custos de transação ocorrido nos últimos 30 anos em virtude das novas tecnologias de informação.

Para competir neste ambiente, as empresas de qualquer país precisam dispor de recursos materiais e institucionais para lidar com ambos os fenômenos. Do lado dos investimentos em P\&D, acentuaram-se as três características principais descritas no artigo clássico de Arrow (1962): [a] as economias de escala e escopo inerentes a estas atividades; [b] o grau de incerteza quanto aos resultados a serem obtidos; [c] o risco de que as inovações geradas pela empresa sejam apropriadas rapidamente pelos concorrentes. Do lado dos métodos de produção, a terceirização de atividades e a formação de parcerias estáveis com provedores de insumos, componentes e serviços diversos só serão rentáveis sob determinadas condições da economia doméstica, que incluem a qualidade da infraestrutura de transportes, a estrutura de proteção aduaneira, a agilidade e segurança jurídica do ambiente de negócios.

Nos últimos 10 anos, o governo brasileiro adotou uma série de providências que, em princípio, seriam destinadas a enfrentar os desafios acima referidos. Em 2004 foi lançada a PITCE (Política Industrial, Tecnológica e de Comércio Exterior), composta de 57 medidas distribuídas em 11 programas setoriais, e que foi amparada pela edição da Lei no 10.973/04 — a Lei de Inovação Tecnológica — e pela criação de dois novos órgãos: o Conselho Nacional de Desenvolvimento Industrial e a Agência Brasileira de Desenvolvimento Industrial. Uma nova iniciativa foi anunciada em maio de 2008, a Política de Desenvolvimento Produtivo - PDP, com quatro metas previstas para 2010: [i] elevar a taxa de investimento para $21 \%$ do PIB; [ii] ampliar a participação das exportações brasileiras para 1,25\% do comércio mundial; [iii] expandir os gastos privados em P\&D; [iv] aumentar o número de pequenas e médias empresas exportadoras. Em 2011 foi a vez do Plano Brasil Maior, que ratificou e ampliou os objetivos anunciados nas duas iniciativas anteriores, a PITCE e a PDP. Em 2012 surgiu um quarto plano, o Inovar-Auto, que atualizou o escopo dos benefícios tributários concedidos à indústria automobilística - mantendo uma tradição estabelecida no país desde a década de 1950.

Entretanto, uma análise do desempenho da indústria no período 1996-2011 não revela qualquer impacto daquelas iniciativas sobre os índices de competitividade internacional dos distintos setores. De fato, a heterogeneidade dos indicadores nesse período parece estar mais associada às especificidades de cada ramo - como capacidade inovadora das firmas locais, poder de mercado, ritmo de expansão da demanda doméstica e/ou internacional, dotação de recursos naturais, etc. — do que aos planos lançados pelo governo (Rios e Tavares, 2013).

Tais resultados são aparentemente enigmáticos porque, atualmente, a economia brasileira dispõe das instituições que, segundo as previsões da teoria, deveriam asse- 
gurar a efetividade da política industrial, provendo dois recursos fundamentais. O primeiro é aquele cumprido pelo Conselho Administrativo de Defesa Econômica (CADE), ao preservar a transparência das condições de concorrência no mercado doméstico e coibir condutas unilaterais ou concertadas que prejudiquem a ordem econômica. Conforme mostram de forma eloquente os trabalhos de Acemoglu et al. (2013) e Aghion et al. (2012), na ausência de um órgão encarregado da defesa da concorrência, os incentivos da política industrial se tornam inúteis. O segundo recurso é aquele oferecido pelo BNDES, a FINEP, os institutos de pesquisa tecnológica e demais mecanismos operados pelo Ministério de Ciência, Tecnologia e Inovação (MCTI), cujo papel é lidar com as questões apontadas por Arrow (1962) e absorver, através do gasto público, uma parcela dos riscos dos investimentos privados em P\&D.

A origem deste aparente enigma é sabida: embora o país disponha de instrumentos adequados de defesa da concorrência e de incentivo à inovação, o governo vem insistindo, sobretudo desde 2006, em promover políticas que anulam a eficácia daqueles instrumentos, como a manutenção de uma estrutura de proteção aduaneira que prejudica a competitividade de vários setores industriais, regras de conteúdo local que elevam os custos dos investimentos, medidas antidumping que fortalecem o poder de mercado dos oligopólios que atuam nas indústrias de bens intermediários, uso de tributos domésticos para restringir importações e alterações frequentes na lista de exceções da Tarifa Externa Comum do Mercosul (TEC). Os danos provocados por esses mecanismos herdados da era da substituição de importações já foram apontados por diversos autores, assim como as dificuldades em removê-los (Bacha, 2013; Cindes, 2013; Motta Veiga et al., 2013).

Este artigo procura mostrar que algumas mudanças necessárias para romper o impasse atual não são complexas, nem requerem longos períodos de implantação. Esta distinção é útil porque, como ilustram os dois casos abordados a seguir, a eliminação desses entraves teria efeitos positivos imediatos, e isso facilitaria a execução das demais reformas. Os exemplos selecionados são as ações antidumping, que passaram a ser adotadas de forma descontrolada a partir de 2006, como indica a próxima seção, e o uso do critério de Processo Produtivo Básico (PPB) como contrapartida à concessão de incentivos fiscais, que se revelou um instrumento irrelevante de política industrial, como descreve a terceira seção. Por fim, a última seção resume os argumentos do texto.

\section{PROTEÇÃO ANTIDUMPING A MONOPÓLIOS E OLIGOPÓLIOS}

Ações antidumping são instrumentos de proteção típicos de economias abertas. Nas últimas três décadas, a difusão internacional destas medidas esteve diretamente vinculada aos processos de liberalização comercial, como vários autores já assinalaram (Miranda, Torres e Ruiz, 1998; Blonigen e Prusa, 2001; Tavares, Macario e Steinfatt, 2001). Elas começaram a ser usadas em meados dos anos 1970, justamente após a eliminação generalizada de barreiras comerciais entre as economias avançadas, que havia sido promovida pelas sucessivas rodadas de negociações 
multilaterais do GATT (Acordo Geral de Tarifas e Comércio) a partir de 1947. Assim, até o final da década de 1980, os únicos usuários frequentes de medidas antidumping eram Estados Unidos, União Europeia, Canadá e Austrália.

Um novo ciclo iniciou-se na década de 1990, desta vez estimulado pelas reformas comerciais unilaterais executadas por vários países a partir de meados dos anos 1980. O ponto de inflexão ocorreu em 1993, com a emergência de seis novos usuários importantes de medidas antidumping: África do Sul, Argentina, Brasil, Coreia, Índia e México. No caso do Brasil, por exemplo, a legislação antidumping foi introduzida em 1987, com o objetivo explícito de criar mecanismos compensatórios para o processo de abertura comercial que iria começar com a reforma da tarifa aduaneira em 1988.

Numa economia aberta, a função cumprida pelas medidas antidumping é a de conferir proteção seletiva e temporária àquelas indústrias que não estão preparadas para enfrentar a concorrência de importações. Durante a segunda metade do século, as normas multilaterais passaram por sucessivas adaptações, para permitir que os governos tivessem a liberdade de recorrer a este mecanismo quando julgassem conveniente, conforme apontaram Blonigen e Prusa (2001). O aprimoramento das regras demandou um paciente esforço diplomático, ao longo de várias rodadas de negociações no GATT e, posteriormente, na Organização Mundial do Comércio (OMC), visando a conciliar duas metas que, em princípio, eram conflitantes. Por um lado, a fim de evitar disputas comerciais indesejáveis, era preciso definir procedimentos objetivos e transparentes, baseados em conceitos claros sobre a prática de dumping, os danos sofridos pela indústria doméstica, e o vínculo causal entre os dois fenômenos. Por outro lado, os governos procuravam assegurar uma autonomia plena para aplicar estas normas de acordo com suas prioridades domésticas ${ }^{1}$.

O governo norte-americano, por exemplo, não aplicou uma única medida antidumping durante a década de $1950 . \mathrm{Na}$ década seguinte, a mesma orientação prevaleceu em $90 \%$ dos casos abertos. As razões desta conduta eram bem conhecidas, e dispensavam um anúncio formal: naquele período, um dos objetivos prioritários da política econômica externa dos Estados Unidos era o de completar a remoção das barreiras comerciais multilaterais que haviam sido criadas durante a grande depressão dos anos trinta. Logo, se o governo fosse leniente com as

\footnotetext{
${ }^{1}$ A necessidade de harmonizar estas duas metas de forma pragmática sempre foi defendida pela maioria dos membros da OMC e, em particular, pelo governo dos Estados Unidos: "Contrary to the assumptions of some economists, the antidumping rules are not intended as a remedy for the predatory pricing practices of firms or as a remedy for any other private anti-competitive practices typically condemned by competition laws. Rather, the antidumping rules are a trade remedy which WTO Members have agreed is necessary to the maintenance of the multilateral trading system. Without this and other trade remedies, there could have been no agreement on broader GATT and later WTO packages of marketopening agreements, especially given imperfections which remain in the multilateral trading system" (U.S. Government, 1998, p. 2)
} 
pressões protecionistas domésticas, suas posições no âmbito do GATT perderiam credibilidade.

Da mesma forma, o Brasil praticamente não usou este tipo de instrumento entre 1993 e 1995. Em 1993, das 26 investigações abertas, 24 foram encerradas sem aplicação de direitos. Em 1994, o governo aprovou três medidas sobre as importações de ferrocromo baixo carbono (NCM 7202.49) provenientes do Cazaquistão, Rússia e Ucrânia. Em 1995, apenas uma petição foi acolhida, coincidentemente sobre o mesmo produto, dando origem a cinco investigações contra os produtores da Bósnia, Croácia, Eslovênia, Iugoslávia e Macedônia. Ou seja, entre outubro de 1993 e agosto de 1995, somente um produto recebeu proteção antidumping no Brasil, conforme registram os relatórios anuais do Departamento de Defesa Comercial (DECOM) do Ministério do Desenvolvimento, Indústria e Comércio Exterior (MDIC) (www.mdic.gov.br). Este fato pode ser explicado pelas circunstâncias da época, quando as prioridades do governo estavam concentradas no Plano Real, na formação do MERCOSUL e na continuidade da reforma comercial implantada pelo governo Collor.

$\mathrm{Na}$ década passada, o padrão de conduta acima descrito foi mantido entre 2002 e 2005, quando, em média, eram abertas sete investigações por ano (Gráfico 1). A partir do ano seguinte, o governo brasileiro tornou-se gradualmente um dos principais usuários de antidumping entre os membros da OMC. De 2007 a 2013, o número de investigações abertas superou o total registrado nos 18 anos anteriores de existência deste instrumento no país: 203 contra 193. Só em 2013, foram iniciados mais casos (54) do que nos quatro anos do primeiro mandato do Presidente Lula (32). Segundo os relatórios da OMC, que atualmente reúne 159 países, entre julho de 2012 e junho de 2013 o Brasil foi, pela terceira vez consecutiva, o líder mundial na abertura de investigações antidumping, com um número de casos superior aos do Canadá, Estados Unidos e União Europeia em conjunto (Gráfico 2).

Gráfico 1: Brasil: Investigações Antidumping Iniciadas (2001-2013)

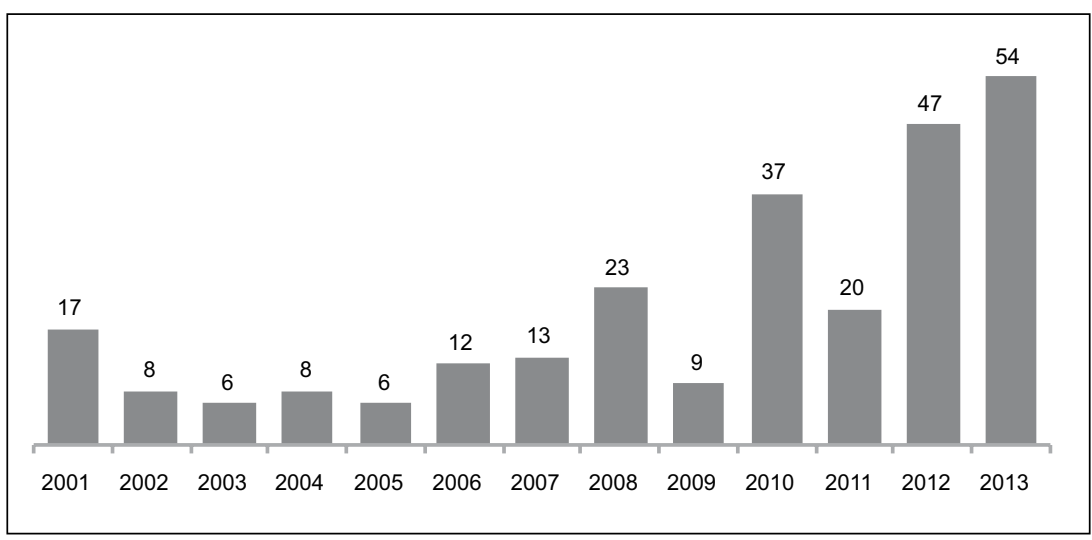

Fonte: Relatório DECOM 2013. 


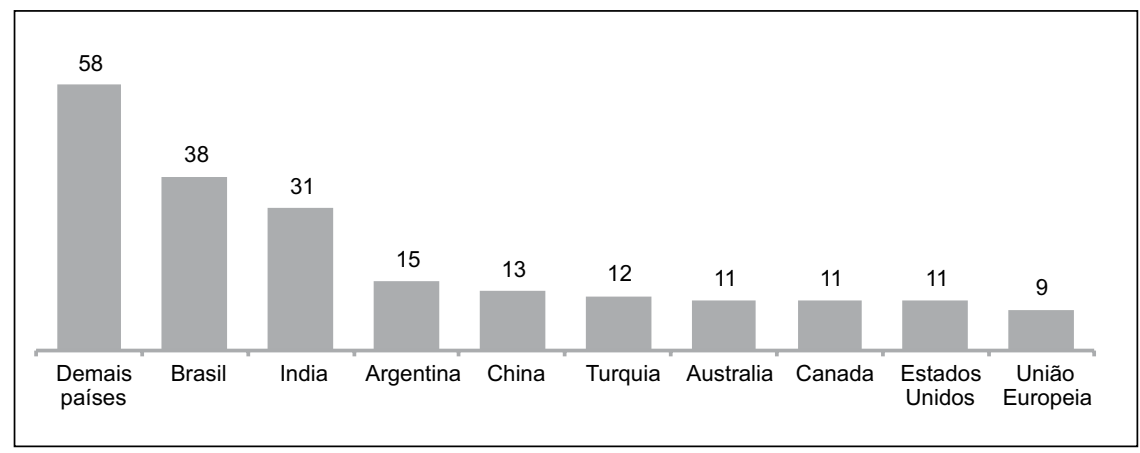

Fonte: OMC.

Este ativismo exacerbou duas características perversas das ações antidumping no Brasil: a proteção a monopólios e oligopólios,e o foco em bens intermediários, sobretudo os produtos químicos e siderúrgicos. Como mostra a Figura 1, entre as medidas vigentes em julho de 2014, $91 \%$ beneficiaram indústrias com até três produtores, sendo que $58 \%$ foram destinadas a monopólios e $24 \%$ a duopólios. Esta distribuição não é muito distinta daquela que vigorou entre 1989 e 2006, quando os monopólios representaram $50 \%$ dos casos, duopólios, $26 \%$, e indústrias com três firmas, $6 \%$. Mas, até 2006, estas medidas eram dirigidas a um número restrito de oligopólios domésticos, em contraste com o descontrole da situação atual, que transformou o país em líder mundial nesta modalidade de protecionismo.

Entre as 70 medidas vigentes em 31.07.2014, 17 amparam bens de consumo final com reduzido impacto nos orçamentos familiares, como alho, sal grosso, escova de cabelos, armações de óculos, cadeados, talheres, objetos de louça, ventiladores de mesa, leite em pó, calçados, etc. Mas, entre as 53 medidas relativas a bens intermediários, ao invés de produtos prosaicos, a proteção abrangeu insumos cujos preços geram impactos generalizados sobre a estrutura industrial do país, como tubos de aço, PVC, vidros planos, resinas de polipropileno, acrilato de butila, pneus de carga, fios de viscose, ácido de sódio, eletrodos de grafite, porcelanato técnico, N-butanol, laminados planos de aço, refratários básicos, magnésio metálico, etc.

De fato, no caso de bens intermediários, as medidas antidumping apenas elevam o patamar de proteção conferido no Brasil a estas indústrias, que já é um dos mais altos do mundo (Baumann e Kume, 2013; Tavares e Costa, 2010). Além de onerar os custos de produção das indústrias usuárias, tais medidas podem distorcer as condições de concorrência em alguns segmentos da economia. Com frequência, a firma que solicita uma medida antidumping para determinado insumo também fabrica produtos a partir daquele insumo (por exemplo: acrilato de butila e tintas; PVC e produtos de plástico; fios de viscose e tecidos). Logo, a peticionária é beneficiada duplamente através da medida, que reduz a pressão competitiva das importações no mercado do insumo e eleva os custos de produção de seus concorrentes no mercado a jusante. 
Figura 1:

Perfil das Indústrias Protegidas por Direito Antidumping

Medidas Vigentes em Julho de 2014

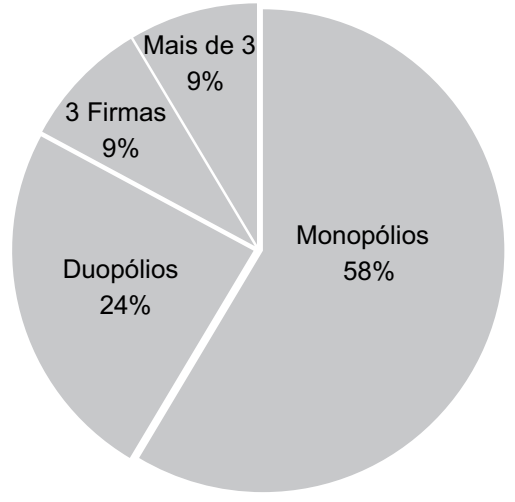

Investigações Iniciadas entre 1989 e 2006

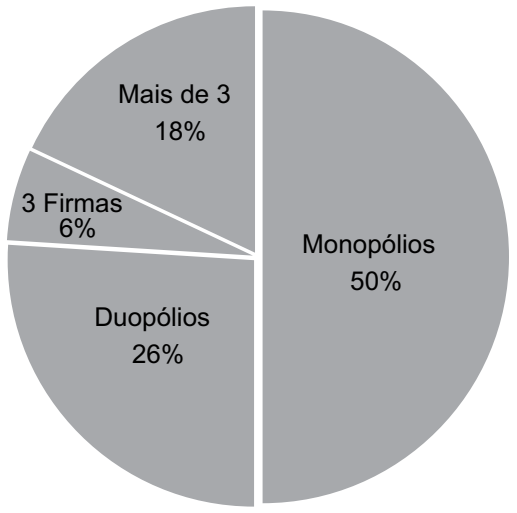

Fonte: www.mdic.gov.br.

\section{O USO DE PPB E SUAS CONSEQUÊNCIAS}

Regras de conteúdo local têm uma longa tradição no Brasil, que foi iniciada através do Decreto-Lei no 947, de 04.11.1890, que proibia a redução de tarifas aduaneiras para produtos com similar nacional (Malan et al., 1977). Aquele Decreto-Lei deu início a uma prolífica experiência ao longo do século XX, que 
adquiriu complexidade crescente a partir do Plano de Metas do governo Kubitschek (1956-1961). Todavia, o governo Collor (1990-1992) introduziu uma nova safra de requisitos de conteúdo local através da Lei no 8387/91, que definiu o conceito de PPB nos seguintes termos: "O conjunto mínimo de operações, no estabelecimento fabril, que caracteriza a efetiva industrialização de determinado produto". Cada PPB é estabelecido através de portarias conjuntas dos Ministérios de Ciência, Tecnologia e Inovação (MCTI) e do Desenvolvimento, Indústria e Comércio Exterior (MDIC), e serve de contrapartida aos benefícios fiscais concedidos nos âmbitos federal, estadual e municipal. Uma peculiaridade desse instrumento é que a definição do PPB de cada produto não é feita pelo governo, mas pela firma interessada em obter os incentivos fiscais. Entre 1993 e 2012, foram publicadas cerca de 1.300 portarias relativas a mais de 600 produtos, cuja maioria se concentra nas indústrias de bens de informática, máquinas e equipamentos, e material elétrico.

Segundo informa o site do MDIC (www.mdic.gov.br), ao definir uma portaria de PPB, o governo considera sete critérios principais:

i. montante de investimentos a serem realizados pela empresa para a fabricação do produto;

ii. desenvolvimento tecnológico e engenharia local empregada;

iii. nível de empregos a ser gerado;

iv. perspectiva de exportações do produto a ser incentivado;

v. nível de investimentos em P\&D;

vi. eventual deslocamento de produção dentro do território nacional em virtude dos incentivos fiscais;

vii. eventual impacto sobre os investimentos de outras empresas do mesmo segmento industrial advindo do aumento de competitividade gerado pelos incentivos fiscais.

Assim, os critérios acima teriam sido responsáveis, em princípio, pelo atual perfil de distribuição setorial dos incentivos fiscais (Figura 3). Em 2012, cerca de $70 \%$ das portarias em vigor se concentraram em três indústrias: bens de informática $(42 \%)$, material elétrico (18\%), e máquinas e equipamentos $(9 \%)$. Tomando-se por referência o total de renúncia fiscal gerado em 2011 pelas portarias relativas a bens de informática, que foi de $\mathrm{R} \$ 3,8$ bilhões, segundo o Tribunal de Contas da União (TCU) ${ }^{2}$, e a média anual de portarias publicadas desde 2001, é possível estimar, conservadoramente, que, em conjunto, estas três indústrias tenham recebido cerca de R $\$ 60$ bilhões de benefícios fiscais nos últimos 13 anos, em valores cor-

\footnotetext{
${ }^{2}$ Em 2013, o TCU realizou uma auditoria operacional a respeito das portarias de PPB no setor de informática.
} 
rentes de $2011^{3}$. Na verdade, este montante representa apenas uma pequena parcela dos gastos tributários criados pelas portarias de PPB. Em 2011, somente na Zona Franca de Manaus, os benefícios concedidos alcançaram R \$20,3 bilhões, de acordo com a Receita Federal do Brasil (RFB) ${ }^{4}$.

Figura 3: Portarias de PPB Vigentes em 2012: Distribuição por Setores Industriais

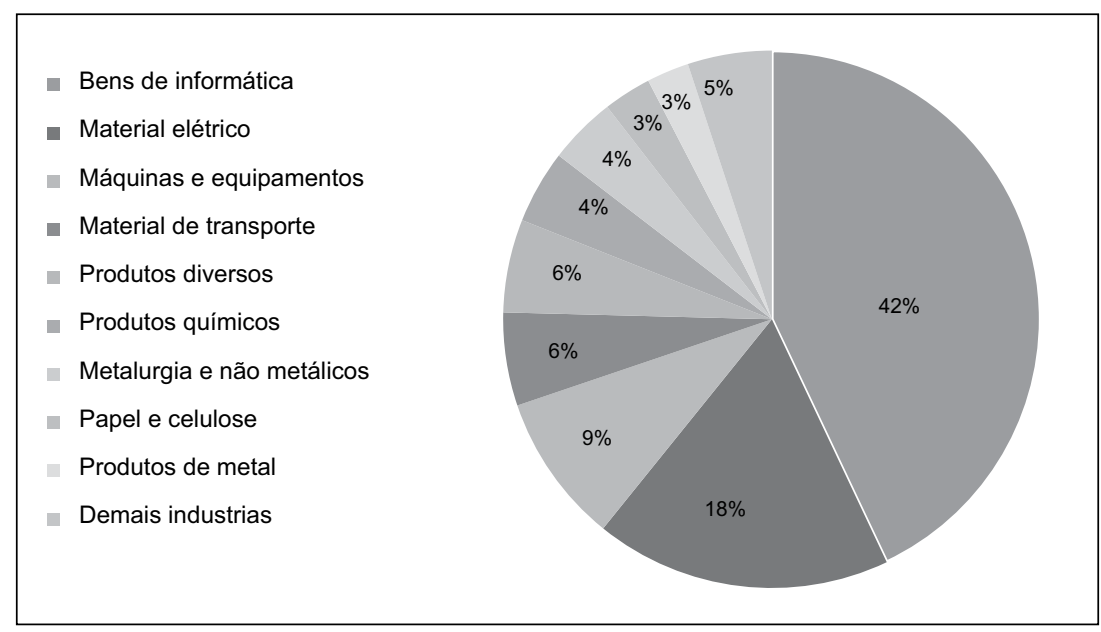

Fonte: http://inicio.com.br/ppbs/5.

Todavia, as evidências disponíveis mostram que tais benefícios não geraram impactos relevantes sobre os níveis de competitividade internacional destas indústrias. Como registra o Quadro 1, entre 1996 e 2011 os coeficientes de penetração de importações cresceram muito nos três casos. Em bens de informática, passou de 23,9\% para $51,8 \%$, em material elétrico, de $18,5 \%$ para $34 \%$, e em máquinas e equipamentos, de $5 \%$ para $40,8 \%$. Em tese, estas mudanças deveriam indicar sinais positivos, ao sugerir uma integração maior da indústria doméstica ao mercado internacional, desde que tivessem sido acompanhadas de elevações correspondentes nos coeficientes exportados. No entanto, não obstante o crescimento do coeficiente de bens de informática, que alcançou o modesto nível de $9,7 \%$ em 2011, não houve alteração relevante no caso de

\footnotetext{
${ }^{3}$ A estimativa dos benefícios totais foi feita com base em duas hipóteses. A primeira é a de que os subsídios concedidos em cada ano sejam proporcionais ao número de portarias vigentes naquele ano. A segunda é a de que, em conjunto, as demais indústrias recebam a metade do valor alocado à indústria de informática. Além disso, os montantes obtidos para o período 2001-2013 foram deflacionados pelo IPCA.

${ }^{4}$ O relatório dos gastos tributários do governo federal no período 2009-2013 está disponível em www. receita.fazenda.gov.br/publico/estudotributario/BensTributarios/2011/DGTEfetivo2011Serie2009a2013. pdf.

${ }^{5}$ Nos sites do MDIC e do MCTI não existem informações completas sobre as portarias de PPB publicadas desde 1993. O portal http://inicio.com.br, organizado por Rogério Sampaio Parente Vianna, servidor aposentado do MCTI, contém uma base de dados com todas as informações relevantes para o período 1993-2012.
} 
material elétrico $(13,1 \%$ para $12,8 \%$ ), enquanto o coeficiente exportado de máquinas e equipamentos foi reduzido a menos da metade $(16,6 \% \text { para } 6,1 \%)^{6}$.

Quadro 1: Indicadores de Competitividade Internacional: 1996 - 2011

\begin{tabular}{|l|r|r|r|c|}
\hline \multirow{2}{*}{ Ramo Industrial } & \multicolumn{2}{|c|}{ Coeficiente exportado } & \multicolumn{2}{c|}{ Coeficiente importado } \\
\cline { 2 - 5 } & 1996 & 2011 & 1996 & 2011 \\
\hline & 3,5 & 9,7 & 23,9 & 51,8 \\
Bens de Informática & 13,1 & 12,8 & 18,5 & 34,0 \\
Material Elétrico & 16,6 & 6,1 & 5,0 & 40,8 \\
Máquinas e Equipamentos & & & & \\
\hline
\end{tabular}

Fonte: Fundação Centro de Estudos do Comércio Exterior (FUNCEX).

Apesar da concentração dos incentivos fiscais nestas três indústrias, as portarias de PPB abrangem virtualmente todos os ramos da indústria de transformação, incluindo bens de distintos graus de sofisticação tecnológica, tais como: cartas de jogar, relógios, óculos, binóculos, telescópios, bicicletas, motocicletas, motonetas, automóveis, jipes, cosméticos, brinquedos, produtos de plástico e isopor, bolas e raquetes para tênis de mesa, de praia e de quadra, enfeites de Natal, carrinhos de bebê, tampas de alumínio, fitas adesivas, repelente elétrico, produtos metalúrgicos, papel higiênico, tintas, biodiesel, vinagre, aparelhos de ginástica, postes de fibra de vidro, instrumentos musicais, etc.

Conforme mostra o Gráfico 3, o ritmo de publicação de portarias foi irregular nos últimos 20 anos, embora seja possível notar três fases distintas no uso desse instrumento: [ $i$ ] a década de 1990, quando os incentivos concedidos foram esporádicos; [ii] o período de expansão, entre 2001 e 2009, quando foram editadas, em média, 100 portarias por ano; [iii] o período de retração, entre 2010 e 2012, quando a média caiu para cerca de 60 portarias por ano.

Outro aspecto importante é que, até 2004, a maioria das portarias visava definir novos processos produtivos. Daí em diante, o objetivo prioritário passou a ser o de modificar regras estabelecidas em portarias anteriores, a fim de ajustà-las às tecnologias usadas por novos beneficiários deste instrumento ou para atender a solicitações de beneficiários antigos. Das 550 mudanças introduzidas até 2012, 346 foram relativas a bens de informática. Em outros setores, as alterações são frequentemente prosaicas, como ilustram os casos de confecções e papel higiênico, descritos no Quadro 2.

\footnotetext{
${ }^{6} \mathrm{O}$ coeficiente exportado é a relação entre o valor das exportações do ramo industrial e o valor da produção doméstica. O coeficiente de penetração das importações é calculado pela divisão do valor das importações de produtos do ramo pelo consumo aparente daqueles bens no mercado doméstico.
} 


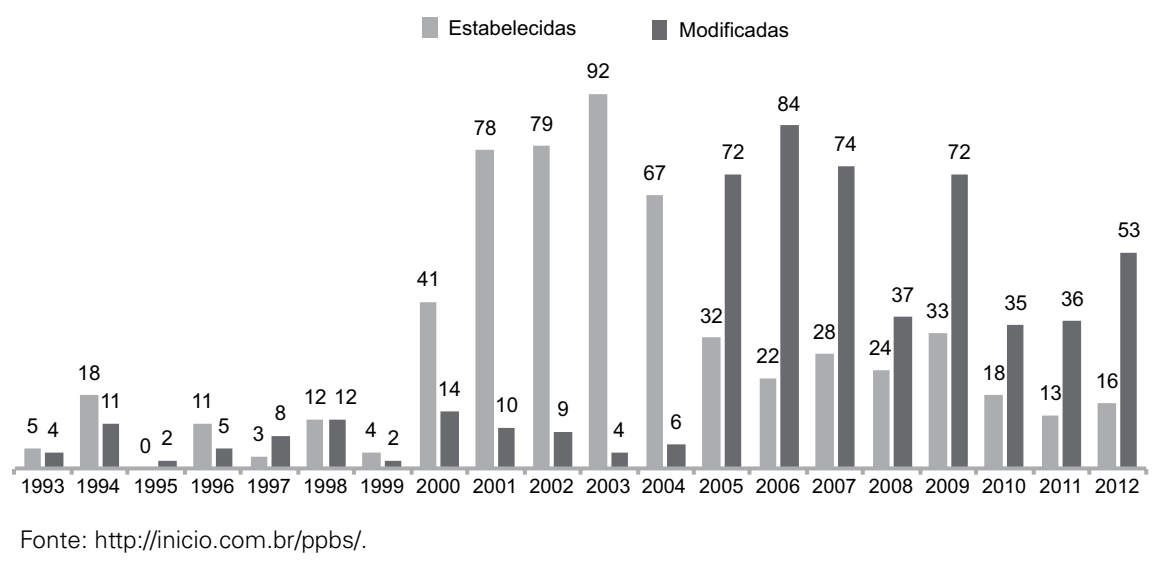

Quadro 2: Os Processos Produtivos Básicos de Confecções e Papel Higiênico

- A partir da Portaria no 222, de 10.10.2001, o processo produtivo básico do setor de confecções, quando realizado na Zona Franca de Manaus, passou a incluir as seguintes etapas:
i. riscar;
ii. cortar;
iii. chulear, quando aplicável;
iv. costurar;
v. casear, quando aplicável;
vi. acabamento.

Este PPB é idêntico àquele que havia sido definido no ano anterior através da Portaria $n^{\circ}$ 31/00, com exceção das etapas [iii] e [v], que agora são opcionais. Foram mantidas as demais exigências quanto a usar no minimo $80 \%$ de tecidos nacionais, realizar todas as etapas em Manaus, e não terceirizar pelo menos uma delas.

- O PPB de papel higiênico também foi objeto de duas portarias: $n^{-} 41$, de 16.01.2004, e $n^{\circ}$. 204, de 13.11.2007. Na primeira portaria, duas rotinas distintas são definidas para papel higiennico em folhas e em rolos. A primeira rotina inclui também outros produtos de papel, como guardanapo, lenço, toalha e lençol hospitalar. Já a segunda é restrita para papel higiênico e toalha de papel em rolos. A Portaria $n^{\circ}$ 41/04 não contém normas quanto ao uso de insumos importados, exceto no caso de papel em rolo jumbo, quando todos os insumos são obrigatoriamente nacionais. A Portaria $n^{0}$ 204/07 trata de produtos de papel reciclado, e nela o PPB de papel higiênico é definido de forma mais genérica, além de não regular a origem dos insumos.

\footnotetext{
${ }^{7}$ Este gráfico não inclui 68 portarias relativas a mudanças de regras que abrangem várias indústrias na mesma portaria, mas não alteram as rotinas de PPB, ou dizem respeito a concessões temporárias.
} 
Um dos fatores responsáveis pelo elevado número de mudanças de regras é a tentativa, por parte do governo, de superar conflitos de interesses gerados pelas portarias de PPB vigentes. Esse esforço nem sempre é bem-sucedido, como revela o caso de óculos de sol, que ganhou notoriedade na imprensa no final de 2012 (Rios e Motta Veiga, 2012). O PPB deste produto foi estabelecido pela Portaria $n^{\circ}$ 68/00, e já naquele momento alguns empresários do setor teriam preferido regras mais flexíveis, que permitissem, por exemplo, a importação de lentes e hastes. Em 2007 foi elaborada uma proposta de alteração da portaria, mas não foi levada adiante. Finalmente, em novembro de 2012, o governo divulgou a Consulta Pública no 46, a fim de tornar o PPB menos rígido. Esta providência provocou uma reação imediata da Associação Brasileira da Indústria Óptica (Abióptica) que, além de declarações alarmistas, classificando as novas regras como desastrosas, buscou o apoio de deputados federais e de ministros de Estado ${ }^{8}$. Nos meses seguintes, o assunto saiu do noticiário, e, até julho de 2014, nenhuma alteração havia sido feita na Portaria no 68/00.

A principal contribuição da auditoria operacional realizada pelo TCU foi demonstrar a inutilidade das portarias de $\mathrm{PPB}$ como instrumento de política industrial. Após 20 anos de incentivos fiscais ao setor de informática através deste instrumento, o único resultado alcançado foi o estabelecimento de uma indústria montadora, voltada ao atendimento do mercado doméstico, com baixo índice de inovação e precário desempenho exportador (TC 013.747/2013-4, pp. 43-48). Esta avaliação é consistente com as evidências encontradas por Ferreira (2007), que estudou a evolução da indústria de telefonia celular na Zona Franca de Manaus no período 2000-2006. Além de examinar as 92 portarias que haviam sido editadas até então para apoiar a produção de telefones celulares, seus componentes e acessórios, ele levantou os dados de produção de todas as firmas deste ramo que operam em Manaus, e entrevistou os executivos de várias delas. Tal como o relatório do TCU, o estudo de Ferreira (2007) não registrou qualquer inovação tecnológica que tenha sido criada pelos beneficiários das portarias de PPB.

\section{CONCLUSÃO}

Em síntese, as evidências discutidas nas seções anteriores mostram que a aplicação descontrolada de medidas antidumping, tal como vem ocorrendo desde 2006, gera proteção supérflua aos oligopólios que atuam nas indústrias de bens intermediários e prejudica o resto da economia. Por outro lado, uma política industrial baseada em PPB deve ser evitada por quatro motivos principais: [a] é incompatível com os padrões contemporâneos de organização industrial; [b] anula os incentivos oferecidos pela política científica e tecnológica; [c] cria gastos públicos ineficientes;

\footnotetext{
${ }^{8}$ Em 22.11.2012, o deputado federal Arnaldo Faria de Sá (PTB-SP) fez um pronunciamento na Sessão Ordinária da Câmara apoiando os pontos de vista da Abióptica.
} 
[d] provoca litígios desnecessários entre firmas que operam em nichos distintos de uma mesma indústria.

Em contraste com a magnitude dos danos causados por esses dois mecanismos, a correção das anomalias pode ser expedita. No caso de antidumping, não é preciso qualquer providência formal: basta que o governo siga o exemplo de outros países, como Austrália, Canadá, Estados Unidos e União Europeia, que antes usavam intensamente este instrumento e simplesmente mudaram de conduta na última década. $\mathrm{Na}$ verdade, como vimos na segunda seção, o governo brasileiro já adotou esta postura no passando, nos períodos 1993-1995 e 2002-2005. No caso de PPB, basta adotar outros critérios de contrapartida à concessão de benefícios fiscais, como a manutenção de determinados montantes de gastos em P\&D, metas ambientais e esforços de integração regional, conforme sugerido em Tavares (2014).

\section{REFERÊNCIAS BIBLIOGRÁFICAS}

Acemoglu, Daron, Ufuk Akcigit, Nicholas Bloom, e William Kerr. (2013). "Innovation, Reallocation and Growth”, NBER Working Paper no. 18993, (www.nber.org).

Aghion, Philippe, Mathias Dewatripont, Luosha Du, Ann Harrison e Patrick Legros. (2012). "Industrial Policy and Competition”, NBER Working Paper no. 18048, (www.nber.org).

Arrow, Kenneth J. (1962) "Economic Welfare and the Allocation of Resources for Invention”, in The Rate and Direction of Inventive Activity: Economic and Social Factors, Princeton University Press, New Jersey.

Bacha, Edmar. (2013). "Integrar para Crescer: O Brasil na Economia Mundial”, Fórum Nacional, Sessão Especial, Rio de Janeiro, 18 e 19 de setembro de 2013.

Bauman, Renato e Honório Kume. (2013). "Novos Padrões de Comércio e Política Tarifária no Brasil”, in Edmar Bacha e Monica Baumgarten de Bolle [orgs.] O Futuro da Indústria no Brasil, Editora Civilização Brasileira, Rio de Janeiro.

Blonigen, Bruce, e Thomas Prusa. (2001). “Antidumping”, NBER Working Paper no. 8398, (www.nber. org).

Cindes: GT de Política Comercial. (2013) "De volta à autarquia? Antecedentes e quadro atual das políticas comercial e industrial no Brasil”, Centro de Estudos de Integração e Desenvolvimento (Cindes), Rio de Janeiro (www.cindesbrasil.org).

Cohen, Elie. (2006). "Theoretical Foundations of Industrial Policy”, EIB Papers, Vol. 11, no. 1, European Investment Bank, Luxembourg.

Edquist, Charles, e Cristina Chaminade. (2006) "Industrial Policy from a Systems-of-Innovation Perspective”, EIB Papers, Vol. 11, no. 1, European Investment Bank, Luxembourg.

Ferreira, Fernando Antônio Cordeiro. (2007). Avaliação do Processo Produtivo Básico (PPB) na Indústria de Telefonia Celular no Período de 2000 a 2006, Monografia de Especialização, Universidade de Brasília, Centro de Desenvolvimento Sustentável.

Malan, Pedro S., Regis Bonelli, Marcelo de Paiva Abreu e José Eduardo de Carvalho Pereira. (1977). Política Econômica Externa e Industrialização no Brasil (1939/52), IPEA/INPES, Relatório de Pesquisa No. 36, Rio de Janeiro.

Miranda, Jorge, Raul Torres e Mario Ruiz. (1998). “The International Use of Antidumping: 19871997”, Journal of World Trade, Vol. 32, no. 5.

Motta Veiga, Pedro, Sandra Polónia Rios e Leane Cornet Naidin. (2013). "Políticas Comercial e Industrial: o Hiperativismo do Primeiro Biênio Dilma”, Breves Cindes 70, Centro de Estudos de Integração e Desenvolvimento, Rio de Janeiro (www.cindesbrasil.org). 
Rios, Sandra Polónia, e Pedro da Motta Veiga. (2012). "Kafka e a Política Industrial”, O Estado de S. Paulo, 11 de dezembro.

Rios, Sandra Polónia, e José Tavares de Araujo Jr. (2013). "Desempenho Industrial e Vantagens Comparativas Reveladas”, in Edmar Bacha e Monica Baumgarten de Bolle [orgs.] O Futuro da Indústria no Brasil, Editora Civilização Brasileira, Rio de Janeiro.

Tavares de Araujo Jr., José. (2014). “A Zona Franca de Manaus e os Países Andinos”, Ecostrat Consultores, Rio de Janeiro (www.ecostrat.net).

Tavares de Araujo Jr., José, Carla Macario e Karsten Steifatt. (2001). “Antidumping in the Americas”, Journal of World Trade, Vol. 35, no. 4.

Tavares de Araujo Jr., José, e Katarina Costa. (2010). “Abertura Comercial e Inserção Internacional: Os Casos do Brasil, China e Índia”, in Renato Baumann (org.) O Brasil e os Demais BRICs, Ipea, Brasilía.

U.S. Government. (1998). "Observation on the Distinctions between Competition Laws and Antidumping Rules”, Organização Mundial do Comércio, WT/WGTCP/W/88, Genebra. 